\title{
CARACTERIZAÇÃO FISIOGRÁFICA E HIDROLÓGICA DA BACIA DO MANANCIAL DO RIO SANTO ANASTÁCIO.
}

\author{
Stela Rosa Amaral Gonçalves ${ }^{1}$
}

Renata Ribeiro de Araújo²

RESUMO: No presente trabalho utilizou-se o software do INPE chamado Spring (versão 5.2) e imagens do Satélite Landsat para elaboração do mapa de uso e ocupação da terra por meio de uma seguimentação e classificação de imagens. O mapa elaborado foi utilizado como base para obter parâmetros necessários ao calculo do escoamento superficial e consequentemente ao balanço hídrico da Bacia do Manancial do Rio Santo Anastácio. Contudo justificou-se através de geoprocessamento, sensoriamento remoto e parâmetros hidrológicos da bacia hidrográfica a abstração que se realizou por meio de informações visuais e numéricas com auxilio do programa para aplicação em fórmulas que ajudou caracterizar a Bacia como predominantemente composta por pastagens e vegetações de mata ciliar, com um potencial hídrico voltado para a evapotranspiração.

Palavras-chave: Sistema de Informação Geográfica. Balanço Hídrico. Escoamento Superficial.

\section{INTRODUÇÃO}

\footnotetext{
${ }_{1}^{1}$ Graduanda em Engenharia Ambiental, Universidade Estadual Paulista. stelarosaengenharia@gmail.com. 2 Doutora em Ecologia de Ambientes Aquáticos Continentais, Universidade Estadual Paulista, Professora Assistente Doutora. reribeiro@fct.unesp.br.
} 
A unidade territorial Bacia Hidrográfica é um elemento fundamental de análise ao se tratar do ciclo hidrológico em sua fase terrestre.

Para estudo de bacias hidrográficas é fundamental conhecer o ciclo hidrológico, isso porque através dele temos todas as entradas e saídas de água do sistema que integra uma bacia. A principal entrada desse sistema é por meio de precipitação já a saída pode ocorrer em forma de escoamento ou de evapotranspiração.

Para compor um estudo sobre bacias leva-se em consideração sua área, forma, densidade de drenagem, declividade, comprimento do curso principal, tipo de solo, geologia, vegetação uso e ocupação do solo, etc.

Segundo Collischonn (2008); Tassi (2008), a utilização de SIG pode ser muito eficiente para representação de bacias hidrográficas detalhadamente. Para representação de relevo tem-se um modelo digital de elevação obtido durante uma missão do ônibus espacial da NASA está disponível gratuitamente na Internet denominado SRTM (sigla para Shuttle Radar TopographyMission), apresenta uma resolução espacial de cerca de $90 \mathrm{~m}$. Esta representação pode ser utilizada tranquilamente para complementar a caracterização da bacia.

Segundo esse mesmo autor citado a cima o tipo da vegetação, uso e ocupação do solo e tipo do solo são características que influenciam diretamente na formação do escoamento superficial e evapotranspiração, isso porque quando ocorre uma precipitação sabe-se que parte da água fica retida na vegetação, outra parte infiltra e uma terceira parte escoa.

Desta forma a porção retida na vegetação poderá ser absorvida pela mesma ou sofrer evapotranspiração em proporções que vão depender do tipo de uso e ocupação do solo. Já a parcela que infiltra pode ficar armazenada nos poros do solo que vai depender diretamente do seu tipo do solo ou pode encontrar o nível do freático alimentando assim as águas subterrâneas e gerando o escoamento subterrâneo.

Por fim a parte que não fica retida na vegetação e também não penetra no solo vai escoar e assim dar origem ao escoamento superficial que por sua vez alimenta os cursos d'água e represas. 
Em chuvas mais intensas devido a velocidade com que ela chega até a superfície a maior parte dela vai gerar o escoamento superficial, pois não consegue penetrar no solo e escoa instantaneamente ao se chocar com o solo alimentando os cursos d'água e consequentemente suas vazões. Daí a importância de estudar o escoamento superficial que é consequência direta da precipitação e quando ocorre em escalas grandes em tempos pequenos dependendo da região pode causar cheia ou enchentes.

Por meio da avaliação dos parâmetros que caracterizam fisicamente e funcionalmente as bacias hidrográficas tem-se conhecimento dos fatores que determinam a natureza e podem-se fazer comparações entre bacias. Desse modo, o aproveitamento dos recursos hídricos pode ser feito de maneira mais racional com maiores benefícios à sociedade em geral.

Existe uma variabilidade muito grande entre as bacias, portanto cada bacia deve ser estudada pontualmente levando em consideração todas suas possíveis características.

O presente trabalho tem como objetivo estudar fisiográficamente e hidrologicamente a bacia do manancial do rio Santo Anastácio a fim de entender melhor suas características de uso e ocupação e escoamento superficial de modo que esta bacia possa ser mais bem gerenciada e assim o estudo ser ponto de partida para iniciativas de órgãos públicos e empresas privadas que competem a essa área.

\section{MATERIAL E MÉTODO}

Primeiramente para elaboração do mapa de uso e ocupação da terra foram utilizadas imagens do Satélite Landsat5 (órbita/ponto - 222/075) do mês 09/2011, esses dados orbitais foram adquiridos no site do INPE e os mesmos processados no software SPRING (5.2).

Para processamento das imagens primeiramente criou-se um banco de dados e um projeto. Após a escolha das imagens que levou em consideração parâmetros como, por exemplo, a cobertura de nuvens e possíveis ruídos, abriu-se a uma primeira banda no 


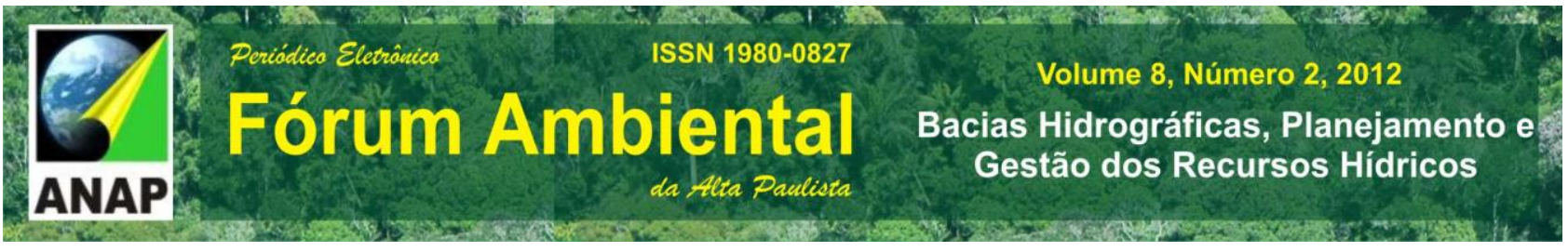

Impima, um aplicativo que vem incorporado no Spring, e recortou-se uma área de interesse da imagem exatamente do mesmo tamanho nas três bandas espectrais banda por banda.

Vale ressaltar que, após o primeiro recorte da área anotou-se os parâmetros de saída da imagem e assim quando foram abertas as outras duas bandas ao invés de recortar a imagem novamente, foram inseridos os valores de $\mathrm{x} 1, \mathrm{y} 1, \mathrm{x} 2$ e y2 obtidos da primeira e o programa encarregou-se de recortar as imagens das outras bandas exatamente do mesmo tamanho.

Feito o recorte as 3 imagens importadas para Spring deram origem ao tamanho do projeto e registrou-se através da opção registro no menu arquivo, sendo as coordenadas dos pontos de controle inseridas por meio do teclado.

Elaborou-se a melhor composição colorida sendo para Banda 3 o azul a Banda 4 o verde e Banda 5 o vermelho depois através do menu imagens na opção transformação RGB->IHS foram geradas as 3 imagens separadas de intensidade, matiz e saturação.

Posteriormente aplicou-se um contraste linear normal no histograma da imagem que representava a componente da cor chamada de intensidade e salvou-se esta imagem contrastada para ser utilizada juntamente com a componente de saturação e matiz na transformação IHS->RGB.

Ao fim do processo de transformação foram selecionadas as 3 imagens do produto da transformação gerando uma imagem sintetizada das 3 bandas que também salvou-se no banco de dados.

A segmentação é um processo para agrupamento de regiões e áreas com valores de pixels semelhantes usada para criar uma malha de áreas que vai ser um guia para escolhas dos polígonos amostrais.

Com a segmentação pode-se iniciar a classificação da imagem escolhendo as amostras de treinamento para que o Spring possa gerar uma imagem classificada nas classes temáticas de uso e ocupação chamadas de vegetação, culturas, água, área urbana, pastagem e solo exposto. Classes estas que se cria em um modelo de dados temático anteriormente a segmentação.

Em seguida selecionada a imagem classificada no menu imagem na opção "executar o mapeamento para classe temática", criou-se um mapa temático a partir de 
uma imagem classificada e finalizou-se o mesmo no Scarta que também é um aplicativo incorporado no Spring. Com a imagem classifica na opção medidas de classe foi possível obter os valores em $\mathrm{Km}^{2}$ de ares para cada classe temática avaliada.

Para se estudar estimar o escoamento superficial resultante de precipitação foi utilizada a equação desenvolvida pelo National Resources Conservatoin Center dos EUA (antigo Soil Conservation Service - SCS). Nesse método precisou-se conhecer a cobertura e uso do solo e tipo do solo da bacia. Baseando-se no Quadro 1 obteve-se os valores para o cálculo do escoamento chamado $\mathrm{CN}$.

Quadro 1 - Valores de Parâmetros CN

\begin{tabular}{|l|l|l|l|l|}
\hline Condição & A & B & C & D \\
\hline Florestas & 41 & 63 & 74 & 80 \\
Campos & 65 & 75 & 83 & 85 \\
Plantações & 62 & 74 & 82 & 87 \\
Zonas comerciais & 89 & 92 & 94 & 95 \\
Zonas industriais & 81 & 88 & 91 & 93 \\
Zonas residenciais & 77 & 85 & 90 & 92 \\
\hline
\end{tabular}

Fonte (COLLISCHONN, W. ; TASSI, R, 2008)

Sendo que:

$A=$ solos arenosos e de alta capacidade de infiltração

$B=$ solos de média capacidade de infiltração

$\mathrm{C}=$ solos com baixa capacidade de infiltração

$\mathrm{D}=$ solos com capacidade muito baixa de infiltração.

Levando em consideração que o solo em geral da região em estudo é o argissolo conforme a Figura 1, e que de acordo com suas características é um solo com baixa capacidade de infiltração optou-se pela coluna C do quadro 1. Definido a coluna calculou- 
se o CN por meio de uma média ponderada de acordo com o tipo de uso e ocupação do Mapa de Uso e Ocupação do Manancial do Rio Santo Anastácio elaborado anteriormente.

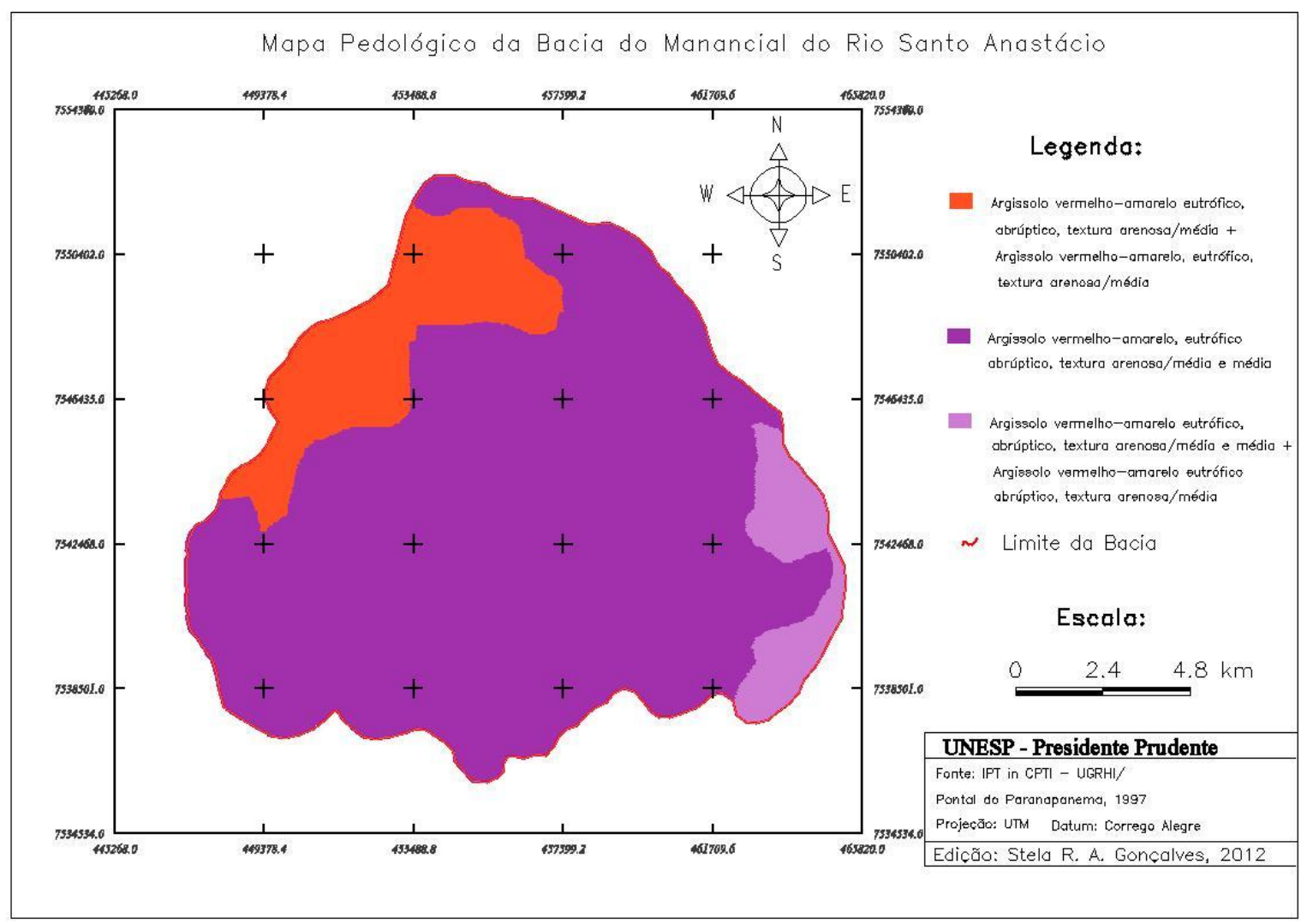

Figura 1 - Mapa Pedológico da Bacia do Manancial do Rio Santo Anastácio

Adotou-se que a classe pastagem e solo exposto seriam representadas pelo valor de campos do quadro 1, bem como a vegetação por florestas, culturas por plantações e área urbana por uma média aritmética de zonas comerciais, industriais e residenciais.

De posse do valor de CN por meio da média ponderada calculou-se o valor de S, parâmetro em função da capacidade de infiltração e armazenamento de água conforme a equação 1.

$$
S=\frac{25400}{C N}-254
$$

(equação 1) 
Sendo:

S - Parâmetro em função da capacidade de infiltração e armazenamento.

$\mathrm{CN}$ - Parâmetro que depende do uso, tipo e cobertura do solo.

Através da equação 2, obteve-se o valor de "la" (estimativa de perdas iniciais de água)

$$
\mathrm{la}=\mathrm{S} / 5 \quad \text { (equação 2) }
$$

Sendo:

la - estimativa de perdas iniciais de água

S - Parâmetro em função da capacidade de infiltração e armazenamento.

Assim com dados de precipitação obtidos e com os parâmetros 'la' e 'S' por meio da formula da equação 3 a seguir pode-se estimar o valor de escoamento, ou seja, tem-se a parcela do total de precipitação que originou um escoamento superficial. Analisando vários eventos chuvosos de uma área pode-se estimar, por exemplo, em um mês ou em um ano a quantidade de água que escoou superficialmente e alimentou os cursos d'água da região.

$$
Q=\frac{(P-I a)^{2}}{(P-I a+S)} \text { quando } P>I a \text { e } Q=0 \text { quando } P \leq I a
$$

(equação 3)

Os dados de precipitação foram adquiridos da estação meteorológica de Presidente Prudente desde junho de 2011 até junho de 2012 e em seguida tabularam-se os dados no Excel para facilitar os cálculos do escoamento.

O balanço entre entradas e saídas de água em uma bacia hidrográfica é denominado balanço hídrico. A principal entrada de água de uma bacia é a precipitação. 
A saída de água da bacia pode ocorrer por evapotranspiração e por escoamento, segundo Collischonn (2008); Tassi (2008) o balanço hídrico de uma bacia exige que seja satisfeita a equação $P=E+Q$ se ocorrer em um intervalo de tempo longo maior ou igual a 1 ano. Onde $P$ é a precipitação em mm.ano-1, E é a evapotranspiração em mm.ano-1 e $\mathrm{Q}$ é o escoamento em mm.ano-1. Em intervalos de tempo longos, como um ano ou mais, a variação de armazenamento pode ser desprezada na maior parte das bacias.

Para facilitar o entendimento dos processos metodológicos do estudo apresentado criou-se o fluxograma apresentado na Figura 2.

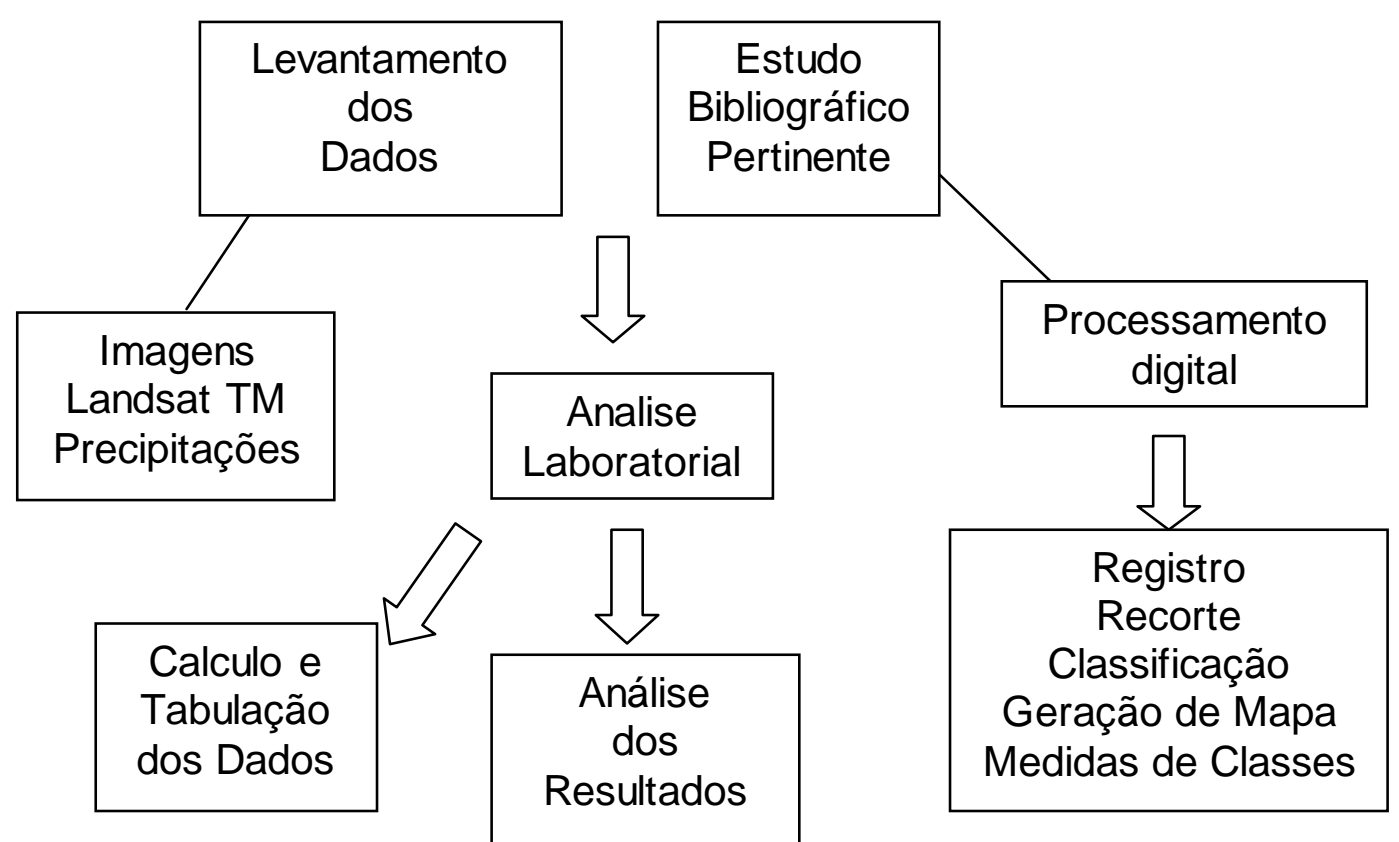

Figura 2 - Fluxograma metodológico

\section{RESULTADOS E DISCUSSÃO}

Após todos os procedimentos e processamentos realizados no Spring finalizou-se o mapa de uso e ocupação da terra da Bacia do Manancial do Rio Santo Anastácio no Scarta, Figura 3. 

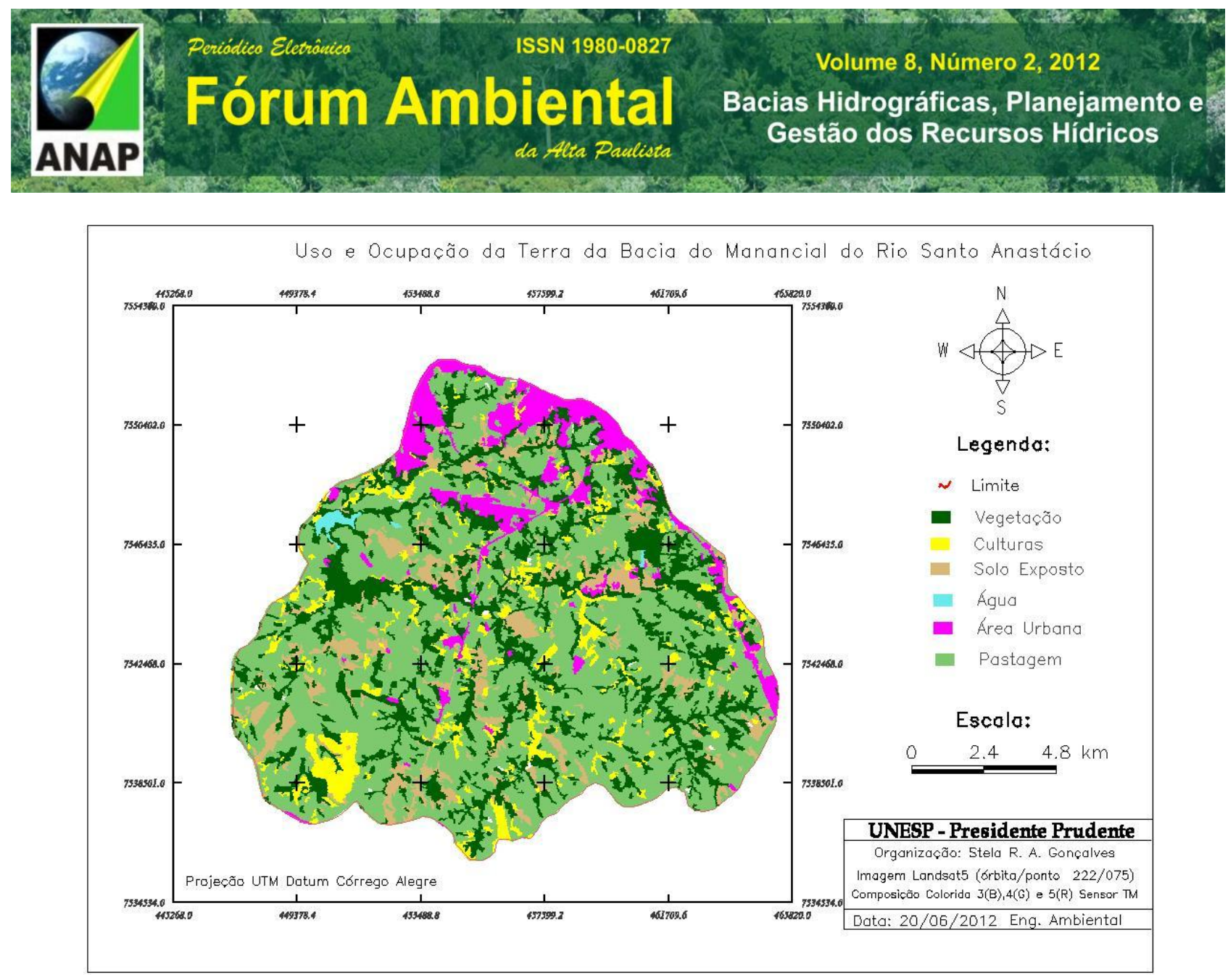

Figura 3 - Mapa de uso e Ocupação da Terra do Manancial do Rio Santo Anastácio

Os resultados da utilização da ferramenta "Medidas de classe" do software que calculou a área em $\mathrm{Km}^{2}$ correspondente a cada classe temática e a porcentagem de área correspondente a cada classe em relação à área total de $198,4 \mathrm{Km}^{2}$ do manancial da bacia em estudo estão dispostos no Quadro 2.

Quadro 2 - Resultados das classes temáticas em porcentagem e de área em $\mathrm{Km}^{2}$

\begin{tabular}{|l|c|c|}
\hline Tipo de Uso e Ocupação & Área em \% & Área em $\mathrm{Km}^{2}$ \\
\hline Pastagem & 52,80 & 104,71 \\
\hline Vegetação & 22,87 & 45,36 \\
\hline Solo Exposto & 9,26 & 18,37 \\
\hline Área Urbana & 7,53 & 14,93 \\
\hline Culturas & 7,15 & 14,18 \\
\hline Água & 0,39 & 0,77 \\
\hline
\end{tabular}


Com os valores decimais correspondentes a porcentagem encontrada de cada classe calculou-se o parâmetro CN da seguinte forma:

$$
C N=\{(0,62 \times 83)+(0,23 \times 74)+(0,075 \times 92)+(0,071 \times 82)\}=81,2
$$

As classes solo exposto e pastagem 0,62 corresponderam a soma dos valores decimais das respectivas classes, ou seja, 0,53 + 0,093 e de acordo com a quadro 1 . Essas classes do mapa foram comparadas ao valor de Campos.

Já para classe vegetação do mapa utilizou-se o valor do quadro 1 correspondente a Floresta, pois a vegetação observada no mapa de uso e ocupação é em geral a mata ciliar que acompanha os cursos d'água.

A classe culturas do mapa relacionou-se com o valor de Plantações do quadro 1. E por fim a classe área urbana do mapa por se tratar de uma mistura de áreas industriais, residenciais e comerciais calculou-se uma média aritmética dos valores dessas 3 Zonas encontrados no quadro 1.

Desta forma, foram calculados os parâmetros para calculo do escoamento superficial, Quadro 3.

Quadro 3 - Valores dos Parâmetros para calculo do escoamento superficial

\begin{tabular}{|l|l|}
\hline Parâmetro & Valor \\
\hline CN & 81,2 \\
\hline S & 58,8 \\
\hline la & 11,8 \\
\hline
\end{tabular}

Calculou-se o escoamento superficial conforme equação 3 e a evapotranspiração de acordo com a relação $P=E+Q$ onde $P$ é a precipitação em mm.ano-1, $E$ é a evapotranspiração em mm.ano-1 e Q é o escoamento em mm.ano-1. Os resultados estão dispostos no Quadro 4. 
Quadro 4 - Resultados do Balanço Hídrico da Bacia do Manancial do Rio Santo Anastácio.

\begin{tabular}{|l|c|c|c|}
\hline Meses & Precipitação $(\mathrm{mm})$ & Esc. Superficial $(\mathrm{mm})$ & Evapotranspiração $(\mathrm{mm})$ \\
\hline Junho (2011) & 41,6 & 4,81 & 36,79 \\
\hline Julho (2011) & 18,2 & 0 & 18,2 \\
\hline Agosto (2011) & 22,8 & 0,094 & 22,706 \\
\hline Setembro (2011) & 6,6 & 0 & 6,6 \\
\hline Outubro (2011) & 193,2 & 20,2 & 173 \\
\hline Novembro (2011) & 116,4 & 27,56 & 88,84 \\
\hline Dezembro (2011) & 154,4 & 20,5 & 133,9 \\
\hline Janeiro (2012) & 179,6 & 46,95 & 132,65 \\
\hline Fevereiro (2012) & 103,2 & 15,45 & 87,75 \\
\hline Março (2012) & 110,2 & 13,88 & 96,32 \\
\hline Abril (2012) & 127,4 & 24,52 & 102,88 \\
\hline Maio (2012) & 111 & 16,29 & 94,71 \\
\hline Junho (2012) & 233,6 & 51,48 & 182,12 \\
\hline Total & 1418,2 & 241,73 & 1176,46 \\
\hline
\end{tabular}

Pôde-se observar que, por meio do mapa de uso e ocupação elaborado, a Bacia do Manancial do rio Santo Anastácio possuiu 52,8 \% de sua área composta por pastagem e em segundo lugar por vegetação predominantemente mata ciliar e concluiu-se que se trata de mata ciliar por sua disposição no mapa ao acompanhar a trajetória dos cursos d'água.

Todavia levou-se em consideração que o valor obtido em porcentagem de 0,39 correspondentes à classe água não foi muito preciso, isso porque a resolução da imagem Landsat foi de 30 metros o que comprometeu a detecção de cursos d'água com largura inferior a resolução da imagem, porém é uma forma rápida de se obter valores fisiográficos e hidrodinâmicos.

Observou-se na tabela de balanço hídrico que do total de $1418,2 \mathrm{~mm}$ que choveu no período de junho de 2011 até junho de 2012 apenas 241,73 mm escoou superficialmente e 1176,46 evapotranspirou. 


\section{CONCLUSÃO}

Observou-se que a elaboração do Mapa de Uso e Ocupação da Bacia do Rio Santo Anastácio foi fundamental para tomada de decisão em relação ao parâmetro $\mathrm{CN}$ e consequentemente para obter o escoamento superficial e balanço hídrico da bacia.

Por meio do balanço hídrico concluiu-se que nessa bacia especificadamente a evapotranspiração foi maior que o escoamento no intervalo de tempo estudado.

É primordial o monitoramento e uso de todas as ferramentas possíveis para manter a qualidade da área do manancial que abasteci a cidade de Presidente Prudente no estado de São Paulo. As construções hidrelétricas devem ter, de antemão, conhecimento desses valores para dimensionar o tamanho dos reservatórios, pois ele deve suportar a carga de todas as chuvas da bacia, pelo menos a maior parte, pois há eventos extremos que são muito pouco frequentes e o custo para incluí-los seria muito desfavorável.

\section{REFERÊNCIAS}

COLLISCHONN, W. ; TASSI, R. Introduzindo Hidrologia. Rio Grande do Sul. UFRGS, 2008.

NOGUEIRA, R. E. Cartografia: representação, comunicação e visualização de dados espaciais. $2^{a}$ Ed. Revisada. Florianópolis: Editora da UFSC, 170p, 2008.

TOMMASELLI, J. T. G. Notas de aula. Presidente Prudente, 2012. 